\title{
Student Blogging about Physics
}

Karen E. Daniels, Department of Physics, NC State University, Raleigh, NC

$\mathrm{I}$ $\mathrm{n}$ traditional introductory physics classes, there is often limited opportunity for students to contribute their own ideas, interests, and experiences as they engage with the subject matter. This situation is exacerbated in university lecture-format classes, where students may not feel comfortable speaking during class. In the last few years, Internet blogs have become a decentralized format for diarists, independent journalists, and opinion makers to both post entries and allow commentary from their readers. Below, I will describe some techniques for using student blogging about physics to engage students from two different classroom environments: a calculus-based introductory mechanics class for scientists and engineers, and an honors seminar for first-year students. These assignments required them to make their own connections between classroom knowledge and situations where it might find applications. A second goal of including blogging in the introductory physics course was to induce students to write about the physics content of the class in a more substantive way than was previously part of the class.

A sample assignment is shown in Fig. 1. Students are asked to post an online image, video, news story, etc. that illustrates the topic of the week. The week's list of topics is usually chosen to cover both previous and upcoming material, for instance, "Conservation of Angular Momentum, Torque, or Temperature." Along with providing a link, the students must write a paragraph describing how their contribution relates to the course content. The blogging provides a number of benefits. Students from diverse majors and backgrounds can present something that interests them personally. In finding a suitable contribution, they are gaining skills in searching the web, evaluating resources for quality, and considering what applications might provide good connections to the week's topic. The accompanying writing, while imperfect, typically exceeds the quality produced for other graded assignments such as labs and exams. This might be attributed to the fact that students know that the content will be public.

How are these student contributions integrated into the course? Many textbook problems describe idealized situations or have already been pre-digested for the students to assume a constant external force or uniform circular motion. By using a student-contributed video from the blog, we can instead base our problem solving on a concrete situation we watch together in class. Students then participate in estimating quantities and deciding what effects to either model or neglect. In a survey conducted at the close of the lecture-based physics class, $44 \%$ of responding students (34 out of 95) would have liked to see more blog-based examples included, and only $12 \%$ would have liked fewer. Finally, by choosing a student-selected example, the instructor is guaranteed that at least one student (and probably more) finds the subject matter interesting. In studies of student blogging, Duda and Garrett ${ }^{1}$ measured that participating students were more likely to maintain positive attitudes toward the subject of study.

In spring 2009, I utilized student blogging in a 100-person calculus-based introductory physics class for scientists and engineers. This class is taught in a largely conventional lecture format that would otherwise have little student-faculty interaction aside from clickers. All students were assigned two separate weeks during the semester when they would need to contribute an entry to the blog. Their contributions were drawn from news articles, physics applets, and videos, with YouTube videos forming the basis for the majority of submissions. Topics covered included automotive devices, break dancers, sports dynamics, Leonard da Vinci, billiard tricks, humorous bloopers, the Earth's mantle, trampolines, silicon wafers, communications satellites, iPhones, guitars,

\section{Assignment 1: Potential Energy and Orbits}

Assignment: Find and post an image, video, news/science story from a newspaper, podcast, etc. that illustrates the week's topic, using the "Comments" feature. Include a paragraph that summarizes the connection to material we've been covering in class, or raises interesting questions relevant to the class.

For help formatting your link so that it is active, see the first post ("Welcome!") which includes instructions. Previewing your entry prior to submission will allow you to check that your link works.

Assigned to: Last names beginning with $\mathrm{T}$ through $\mathrm{Z}$.

Due: Friday, April 24.

Fig. 1. Each week, I post an entry on the course blog, of which I am the sole registered author. Above is a sample assignment posting, which students then respond to in the comments field of the blog, allowing them to remain anonymous if they wish. Collecting a single week's worth of responses in one place makes grading and viewing the student contributions a quick task. 
nanotechnology, alternative energy sources, computer animation techniques, and NASCAR. These were low-stakes assignments: the total impact on their course grade was 0.3 out of 100 points. Nonetheless, $80 \%$ of the students contributed. And $59 \%$ reported that they considered at least three possibilities before making their final selection, evidence that they deemed finding a good contribution worthwhile.

This large-scale deployment had been preceded by a smaller trial (fall 2008) within an honors seminar on chaos. In that class, students posted videos or images associated with each of six themes covered during the semester. Here, the written comments were longer and made more insightful connections to classroom material even though the assignment was the same ("a paragraph"). This reflected both the writingintensive nature of the class (four papers formed the bulk of their grade) and the increased engagement of honors students with the material.

In both cases, the blog was hosted on a site maintained by the NC State Library (http://blogs.lib.ncsu.edu/), but one of the standard blog hosting sites (blogger.com, wordpress.com, etc.) would be able to perform the same functions. By using a pre-existing site as the host, setting up the blog takes no specialized computer skill. Using the NC State Library website had the advantage of support in complying with Family Educational Rights and Privacy Act (FERPA) requirements, which was utilized in the case of the seminar class through students signing waivers. Students in the lecture class were instead asked to write their comments using their eight-letter university identity, thus preserving anonymity. Interestingly, almost all chose to enter their comments using their own names.

The time commitment for grading purposes was limited to marking that students had completed the assignment each week: full credit was granted for on-time participation, rather than quality. Thus, the grading occupied only about $10 \mathrm{~min}$ utes each week, including posting the next week's assigned topics. Because the writing was not graded for content, I made note of any inaccuracies and included a clarification into the lecture content, without reference to the particular student. In this sense, the blog entries played a similar role to Just-inTime Teaching methods. ${ }^{2,3}$ In addition, I spent approximately 30 minutes each week looking at the entries for likely candidates for inclusion in the lectures.

The key difficulty I experienced was that most students simply did not visit the blog to view their classmates' work. While 20-30 hits were generated each day, a survey suggests that these were largely due to students completing the assignment (10-15 hits per week) or external traffic. Because I also made posts of my own connections with material covered in class, I had hoped to generate more traffic. In a future semester, it would be worth exploring incentives to motivate students to view these resources. For example, students might be assigned to provide further commentary on already-posted submissions.

These difficulties were greatly outweighed by the benefits. Just by completing the assignment, independent of other students viewing their entry, students engaged with the physics content in a new context. By using a blog as the medium, students were exposed to some basic HTML and participated in the creation of Web 2.0 content. Several of the contributions chosen as lecture examples were selected for their humorous values, and thus had a positive impact on the class simply by waking students up with laughter. Writing the text accompanying their link required students to use terminology from the class and consider the accuracy of their text before it was made public. This appears to be a strong motivator for producing higher-quality writing since the blog contributions were typically better written than what was observed on the limited "Explain briefly ..." portions of conventional graded labs and exams. Finally, the students whose contributions were selected for use during lectures visibly took pride in having been selected. These initial experiments with student blogging were a success and similar techniques could be applied to a variety of physics classes.

\section{References}

1. G. Duda and K. Garrett, "Blogging in the physics classroom: A research-based approach to shaping students' attitudes toward physics," Am. J. Phys. 76, 1054-1065 (Nov. 2008).

2. G. M. Novak, et al., Just-in-Time Teaching (Prentice Hall, Upper Saddle River, NJ, 1999).

3. J. Higdon and C. Topaz, "Blogs and wikis as instructional tools," Coll. Teach. 57, 105-109 (2009).

Karen Daniels is an assistant professor of physics at NC State University. She has primarily taught introductory physics (including middle and high school physics prior to attending graduate school). Since writing this article, she has integrated similar activities into a graduate student course, where students wrote commentaries on current journal articles related to class material.

Department of Physics, NC State University, Raleigh, NC 27695-8202 karen_daniels@ncsu.edu

\section{PHYSICS \& PHYSICAL SCIENCE at the University of Virginia}

Do you need more physics or physical science content, recertification points, or a physics teacher endorsement? Would you like to have a Master of Arts in Physics Education?

We offer graduate credit professional development courses for $\mathrm{K}-12$ teachers via distance learning throughout the year and summer workshops in Charlottesville. Distance learning courses are completed at home using lectures on CDs and web-based instruction, homework, and testing.

For detailed course information visit www.k12.phys.virginia.edu or email PhysicsEducation@virginia.edu

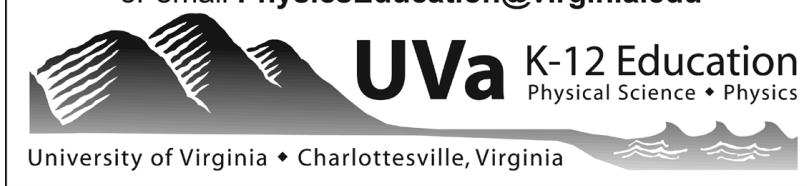

